\title{
TACIT COLLUSION IN DIFFERENTIATED COURNOT GAMES
}

\author{
Birger WERNERFELT \\ Northwestern University, Evanston, IL 60208, USA
}

Received 22 September 1988

Accepted 8 January 1989

In a simple oligopoly with quantity setting firms, we analyze the conditions under which more product differentiation makes tacit collusion easier. It is found that the net effect can go either way.

\section{Introduction}

The relationship between product differentiation and tacit collusion has been analyzed by Deneckere $(1983,1984)$. For Cournot games, he assumed that collusion is supported by the threat of reverting to the equilibrium of the one shot game. Recently, Abreu (1986) has, however, derived the optimal punishment schemes for a wide range of repeated games. The purpose of the present paper is to analyze the collusive effects of product differentiation in the context of optimal punishments.

\section{Model}

We consider a market in which $n+1$ oligopolists compete on quantity and face inverse demand curves of the form

$p_{i}=1-\beta q_{i}-(1-\beta) \sum_{j \neq i}^{n+1} q_{j}, \quad i, j=1,2, \ldots, n+1$,

where $q_{i}$ is the quantity of firm $i$ and increasing values of $\beta \in[1 / 2,1]$ measure increasing product differentiation.

If we conceive of the oligopolists as repeating this game infinitely while discounting their profits according to a 'small' identical rate $r$, we can model tacit collusion as supported by the optimal punishments derived by Abreu (1986, sec. 4). According to his results, the maximum extent of collusion can be characterized by two numbers: $y_{2}$, which is the output per firm in periods not immediately preceded by violations, and $y_{1}$, which is the output per firm in periods immediately preceded by violations (of $y_{2}$ or $y_{1}$ ). Denote the single period profit per firm by $\pi(y)$ if all firms produce $y$, and $\pi^{*}(y)$ if the firm maximizes single period profit given that all others produce $y$. 
Abreu's result is that $\left(y_{1}, y_{2}\right)$ is globally optimal if

$\pi\left(y_{1}\right)=-\frac{1}{r} \pi\left(y_{2}\right)$

$\pi^{*}\left(y_{1}\right)=0$

$\pi^{*}\left(y_{2}\right)-\pi\left(y_{2}\right) \leqslant \frac{1}{r} \pi\left(y_{2}\right)$

The first condition, (2), characterizes the optimal punishment as one which inflicts losses equal to the net present value of all future profits. This is clearly the most severe punishment under which firms will stay in the market. For this to be credible it must furthermore be the case that firms find it (weakly) unattractive to cheat on the punishment. This is captured in (3). By (4) it is finally required that the one-period gains from chcating (which will entail zero net present value thereafter) be weakly dominated by the long-term benefits from the agreement. As long as $y_{2}$ is greater than the cartel output, (4) will hold with equality.

In the absence of production costs, the analogs of (2)-(4) for our model are

$y_{1}-y_{1}^{2}[\beta+(1-\beta) n]=-\frac{1}{r}\left(y_{2}-y_{2}^{2}[\beta+(1-\beta)]\right)$,

$y_{1} \geqslant[(1-\beta) n]^{-1}$,

$\frac{1}{4 \beta}\left[1-(1-\beta) n y_{2}\right]^{2} \leqslant \frac{1+r}{r}\left(y_{2}-y_{2}^{2}[\beta+(1-\beta) n]\right)$.

We will concentrate on the interesting case in which $y_{2}$ is above the cartel output, so we assume

$y_{2}>\frac{1}{2}[\beta+(1-\beta) n]^{-1}$.

This enables us to solve $\left(4^{\prime}\right)$ to find $y_{2}$ as

$$
\begin{aligned}
y_{2}= & {\left[(1-\beta)^{2} n^{2} r+4(1+r) \beta^{2}+4(1+r) \beta(1-\beta) n\right]^{-1} } \\
& \cdot\left[(1-\beta) n r+2 \beta(1+r)-2 \beta(1+r)^{1 / 2}\right] .
\end{aligned}
$$

From this, $\left(2^{\prime}\right)$ can be solved for $y_{1}$, and optimality of the scheme can be checked by seeing if $y_{1}$ satisfies $\left(3^{\prime}\right)$ which always will be the case if $r$ is not too large. So we will conduct our analysis in the intersection of the two sets

$S_{1} \equiv\left\{\left.(\beta, r, n)\right|^{\prime \prime}\right.$ right-hand side of $\left.(5)^{\prime \prime}>\frac{1}{2}[\beta+(1-\beta) n]^{-1}\right\}$,

$S_{2} \equiv\left\{\left.(\beta, r, n)\right|^{\prime \prime}\right.$ the $y_{1}$ solving $\left.\left(2^{\prime}\right)^{\prime \prime} \geqslant[(1-\beta) n]^{-1}\right\}$,

where $S_{1}$ is the area in which it is meaningful to talk about more or less collusion while $S_{2}$ is the domain of optimality for Abreu's scheme. Roughly speaking, $S_{1}$ rules 'too small' values of $r, n$ out, while $S_{2}$ does not allow $r$ to be 'too big'. As an example, $(1 / 2,1,10) \in S_{1} \cap S_{2}$. 


\section{Analysis}

In order to look at the effect of product differentiation on the maximum degree of tacit collusion, we can vary $\beta$ in

$$
\begin{aligned}
& \frac{1}{4 \beta}\left[1-(1-\beta) n y_{2}\right]^{2}-\frac{1+r}{r}\left(y_{2}-y_{2}^{2}[\beta+(1-\beta) n]\right) \\
& \quad=\pi^{*}\left(y_{2}, \beta, r, n\right)-\frac{1+r}{r} \pi\left(y_{2}, \beta, r, n\right) \equiv F\left(y_{2}, \beta, r, n\right)=0,
\end{aligned}
$$

under the assumption that $(\beta, r, n) \in S_{1} \cap S_{2}$.

To measure the implications of increasing product differentiation, we will differentiate $F(\cdot)$ with respect to $\beta$. To this end, we first find

$$
\begin{aligned}
\frac{\partial \pi^{*}}{\partial \beta} & =\frac{1}{4 \beta^{2}}\left[1-(1-\beta) n y_{2}\right]\left[n y_{2}(1+\beta)-1\right] \\
& =\frac{1}{4 \beta^{2}}\left[-n^{2}\left(1-\beta^{2}\right) y_{2}^{2}+2 n y_{2}-1\right] .
\end{aligned}
$$

This is positive if $(1-\beta) /\left[\left(n\left(1-\beta^{2}\right)\right]<y_{2}<(1+\beta) /\left[\left(n\left(1-\beta^{2}\right)\right]\right.\right.$. We know that $y_{2}<[2 \beta+(1-$ $\beta) n]^{-1}$, the Nash output, and that $y_{2}>\frac{1}{2}[\beta+(1-\beta) n]^{-1}$, the cartel output. Since, $(1+\beta) /[(n(1$ $\left.\left.-\beta^{2}\right)\right] \geqslant[2 \beta+(1-\beta) n]^{-1}$ for all elements of $S_{1} \cap S_{2}$ and $(1-\beta) /\left[\left(n\left(1-\beta^{2}\right)\right] \leqslant 1 / 2[\beta+(1-\right.$ $\beta) n]^{-1}$ except when $n=1$ and $\beta<1$, we have that $\partial \pi^{*} / \partial \beta \geqslant 0$ unless $n=1$ and $\beta<1$. In this latter case, however, $y_{2}(n=1)$ from (5) is below the cartel output if $r<4 \beta / 1-\beta(1+r)^{1 / 2}$. If this is not the case, $y_{1}$ from $\left(2^{\prime}\right)$ is below $(1-\beta)^{-1}$ such that $\left(3^{\prime}\right)$ is violated, so $\partial \pi^{*} / \partial \beta>0$. Intuitively, increased differentiation leaves the firm with a bigger residual demand $\left[1-(1-\beta) n y_{2}\right]$, which dominates the increased slope $(\beta)$ of its inverse demand. So contrary to common intuition, increasing product differentiation offer firms greater temptations to cheat in this model.

We next find

$\frac{\partial \pi}{\partial \beta}=y_{2}^{2}(n-1) \geqslant 0$.

Intuitively, increased differentiation leads, ceteris paribus, to larger profits, such that the optimal punishment $(1 / r) \pi\left(y_{2}\right)$ can be more severe. So, again contrary to common intuition, increasing product differentiation makes it possible to penalize a cheater harder in this model.

For any given element of $S_{1} \cap S_{2}$, we can find $y_{2}$ from (5) and insert (6) and (7) into

$$
\frac{\partial F}{\partial \beta}=\frac{\partial \pi^{*}}{\partial \beta}-\frac{1+r}{r} \frac{\partial \pi}{\partial \beta}
$$

to see how these two effects net out. In general, the penalty effect will be relatively stronger for smaller values of $r$ [because of $(1+r) / r$ ], higher values of $\beta$, and smaller values of $n$ (since $y_{2}$ is of the order $1 / n$ ). Intuitively, penalties count more if $r$ is small, the steeper inverse demand hurts the temptation more as $\beta$ goes up, and the ability to penalize goes down as $n$ increases (and $\pi$ decreases). Conversely, the temptation effect will be relatively stronger for larger $r$, smaller $\beta$, and larger $n$. Again, the sign of $\partial F / \partial \beta$ at any particular point in $S_{1} \cap S_{2}$, can be evaluated from (5)-(7). 
While it is clear that increasing values of $\beta$ correspond to increasing product differentiation, it is not at all clear how one measures 'more' collusion. However, following Deneckere $(1983,1984)$, we look at the critical interest rate implied by $\left(4^{\prime \prime}\right)$. That is, we will ask if increasing $\beta$ s allows a given $y_{2}(n)$ to be maintained for even larger values of $r$. Using the implicit function on ( $\left.4^{\prime \prime}\right)$, we find that

$\frac{\partial F}{\partial r}=\frac{1}{r^{2}}\left(y_{2}-y_{2}^{2}[\beta+(1-\beta) n]\right)>0$.

Accordingly, $\mathrm{d} r / \mathrm{d} \beta>0$, such that more product differentiation allows a given output to be maintained with higher discount rate, if $\partial \pi^{*} / \partial \beta<((1+r) / r) \partial \pi / \partial \beta$, that is, if the penalty effect dominates. Conversely, if $\partial \pi^{*} / \partial \beta>((1+r) / r) \partial \pi / \partial \beta$ such that the temptation effect dominates, then more differentiation requires lower discount rates.

If the firms use the inoptimal Cournot-Nash punishments suggested by Deneckere $(1983,1984)$, the analog of $\left(4^{\prime \prime}\right)$ is

$\pi^{*}\left(y_{2}\right)+\frac{1}{r} \pi^{0}-\frac{1+r}{r} \pi\left(y_{2}\right)=0$,

where the Nash profits $\pi^{0}=\beta[n(1-\beta)+2 \beta]^{-2}$ are increasing in $\beta$ such that the analog of $\partial F / \partial \beta$ is bigger. Since these punishments become less severe as $\beta$ increases, this would tend to make collusion relatively harder in the sense that $d r / d \beta$ is smaller.

\section{Conclusion}

In a simple supergame we have analyzed the effect of product differentiation on the maximum degree of tacit collusion. We find that the net effect can go either way. Loosely speaking, differentiation will tend to favor collusion more when firms are fewer and react faster: conditions which tend to make collusion easy in the first place. While this is the type of result one would expect, it is important to note that the net effect comes about through increasing temptation and penalty effects, instead of the opposite.

\section{References}

Abreu, D., 1986, Extremal equilibria of oligopolistic supergames, Journal of Economic Theory 39, 191-225.

Deneckere, R., 1983, Duopoly supergames with product differentiation, Economics Letters 11, 37-42.

Deneckere, R, 1984, Corrigendum, Economics Letters 15, 385-387. 